\title{
Chapter 7 \\ Mesoscale Analysis of Flash Flood and Sediment Disasters
}

\subsection{Background}

Mountains cover $30 \%$ of the global land area. Floods and droughts account for $70 \%$ of all natural disasters, while flash floods alone make up $50 \%$ of all natural disasters. The losses caused by flash floods are among the two most significant types of loss caused by natural disasters in 105 countries in the world. Evidently, flash floods are the primary type of natural disaster across the globe. China is a mountainous country, with $70 \%$ of its land covered by mountains, far exceeding the global average level. Flash-flood prevention and control zones alone account for $48 \%$ of China's total land area. Deaths from flash floods make up more than $70 \%$ of all the deaths caused by flooding and waterlogging. Manifestly, flash-flood prevention and control has proven to be a relatively formidable task (Wang et al. 2019).

In contrast to normal floods, flash floods are more difficult to identify, predict, and control (Borga et al. 2007), owing to their prominent characteristic that notably differentiates them from normal floods - they involve the combined action of flow and sediment. This action can result in a sharp rise of the riverbed and an abrupt increase in the water level and, thereby, can increase the risk of a disaster or even enable a small flood to cause a large disaster.

For example, due to the discharge of floodwater from the Tangjiashan landslide lake as well as the action of flash floods and debris flows after the Wenchuan earthquake that occurred on May 12, 2008, large amounts of sediment entered the river downstream of the Tangjiashan lake. As a result, the riverbed of the reach in the old Beichuan county (i.e., the Beichuan National Earthquake Ruins) continually silted up and rose. Specifically, due to sedimentation, the riverbed rose cumulatively by 5-10 $\mathrm{m}$ on average and over $20 \mathrm{~m}$ in some areas. After a flash flood that occurred on July 9, 2013, the elevation of the riverbed of this reach resulting from sedimentation reached the top of the flood banks. Consequently, the floodwater spilled over the flood banks and ran to the Beichuan National Earthquake Ruins. As another example, the Boluo Hydropower Station at the confluence of the Wahei River and Xianjiapu River in Mabian County, Sichuan province was completed and put into operation in 
February 1999. Two consecutive years of flash floods from June 6, 2000 to July 28, 2001 resulted in extensive sedimentation in the confluence region, which silted up the rivers. The sedimentation layer reached approximately $5.0-7.5 \mathrm{~m}$ in thickness. As a result, the water level was $6.5 \mathrm{~m}$ higher than the elevation $(822.0 \mathrm{~m})$ of the top of the flood walls. Consequently, the power plant was submerged. The accumulated sediment within the power plant reached $826.5 \mathrm{~m}$. This caused disastrous damage to the power station. Another more typical example took place in a village at the foot of a hill. Small rivers ran on each side of this village. After a heavy rainstorm, one of the rivers severely silted up, and its water level rose considerably. As a result, the half of the village on this side suffered a severe flash flood and sediment disaster (FFSD), which left 24 people dead. No siltation occurred in the river on the other side, and consequently, the half of the village on the other side remained unscathed.

Similar to the analysis in previous chapters, FFSDs are also macroscopic assemblies of mesoscale processes. The key to an FFSD lies in the transition of sediment particles, a type of mesoscale matter, from a moving state to a stationary state, which results in macroscopic sedimentation in a large area, ultimately evolving into a severe flood and sediment disaster (Dietrich et al. 1989; Diplas et al. 2008; Madej et al. 2009). Therefore, thoroughly determining the moving pattern of sediment particles from a mesoscale perspective is imperative for the theoretical investigation, identification, prediction, and engineering control of FFSDs.

Mesoscale analysis of FFSDs entails not only the analysis of the mechanism by which the movement of sediment particles causes disasters but also the analysis of coupled flood and sediment disaster conditions, accurate identification of disasters, simulations of flood and sediment movement and, ultimately, development of techniques to guide the control of FFSDs.

\subsection{Sudden Stop and Accumulation of Sediment Particles After a Hydraulic Jump}

A hydraulic jump is a classical sudden change in a flow. A heuristic understanding can be derived from an analysis of the changes in the movement of sediment particles after a hydraulic jump.

Figure 7.1 shows the sudden stop of sediment particles after a hydraulic jump (images were taken at intervals of approximately $2 \mathrm{~s}$ ). The sediment particles moving at a relatively high velocity with the flow prior to the hydraulic jump suddenly stopped moving and remained on the bed immediately after the hydraulic jump.

Under certain hydraulic jump conditions, single particles of varying sizes stopped suddenly to varying degrees when passing through the hydraulic-jump zone. As shown in Fig. 7.2, relatively large particles were mostly able to stop suddenly at locations close to the hydraulic-jump zone. These particles stopped suddenly within a relatively small area. As the particle size (i.e., median particle diameter $d_{50}$ ) increased, there was a gradual decrease in the number of particles capable of 

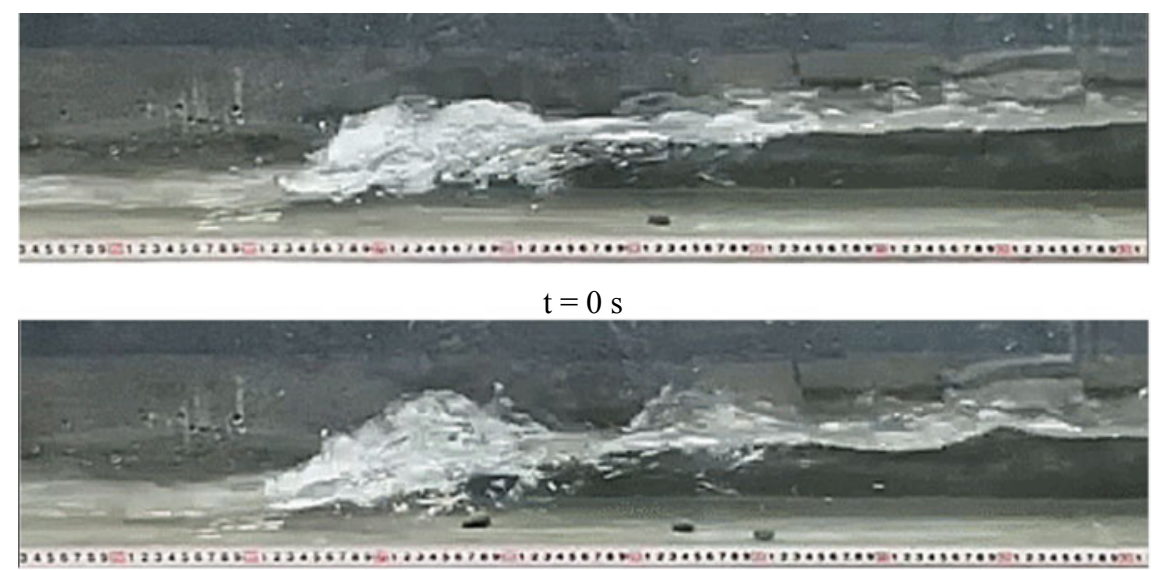

$\mathrm{t}=2 \mathrm{~s}$

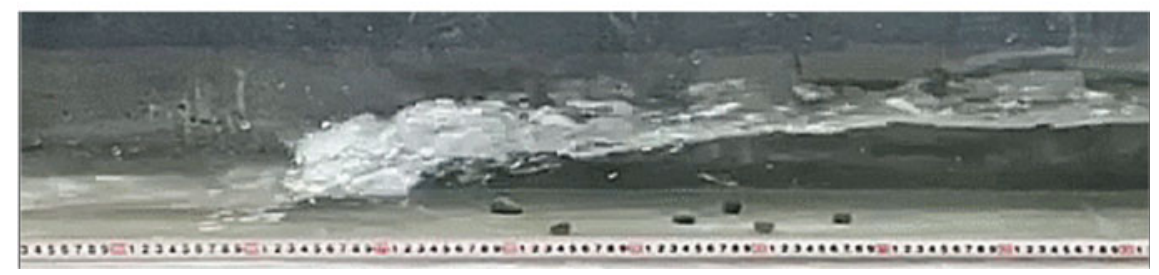

$\mathrm{t}=4 \mathrm{~s}$

Fig. 7.1 Sudden stop of sediment particles after a hydraulic jump

basically remaining at the bottom of the flow, and many particles continued to move downstream, albeit much more slowly than before the hydraulic jump. In addition, as the particle size increased, the area where the particles stopped suddenly gradually moved downstream and increased in size. When the carrying capacity of the flow exceeded the particle size, the particles no longer stopped suddenly.

When there was a relatively large upstream sediment supply, the abovementioned sudden stop of single particles transformed into rapid, extensive sedimentation (Fig. 7.3).

Further observation found that when extensive sedimentation occurred rapidly, the sediment particles were obstructed by the accumulation body upon reaching the toe of its slope and, as a result, climbed upwards along the accumulation body and were eventually deposited on top of it. This further increased the volume of the accumulation body (Fig. 7.4).

Thus, with continuous rapid sedimentation, the local riverbed rose rapidly, and a relatively large adverse slope was formed at the front of the raised section. Subsequent sediment particles were more prone to accumulation upon reaching this adverse slope. This resulted in further upstream development of the raised section of the riverbed, which in turn moved the location of the hydraulic jump upstream. Ultimately, this led to a continuous increase in the area where the riverbed and water level rose (Fig. 7.5). 


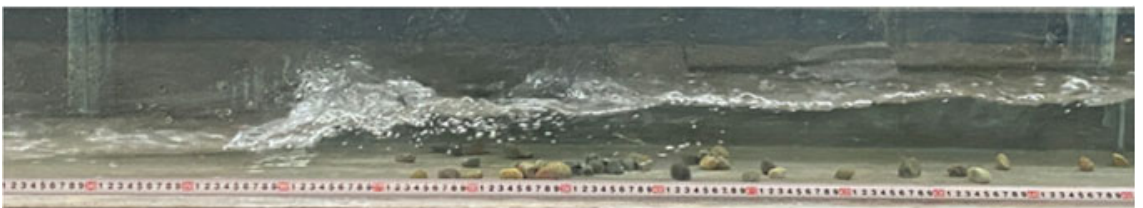

(a) $d_{50}=2.5 \mathrm{~cm}$

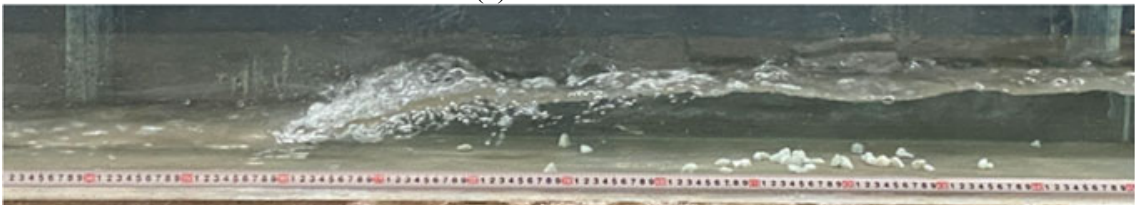

(b) $d_{50}=1.8 \mathrm{~cm}$

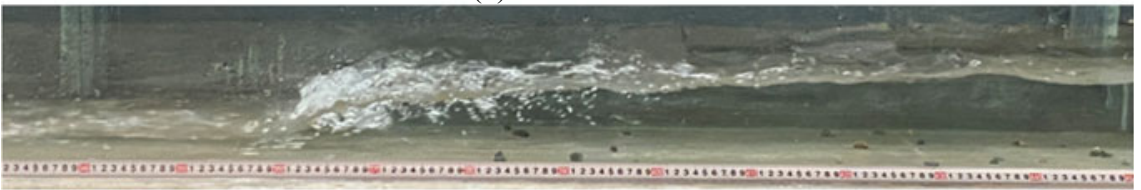

(c) $d_{50}=1.5 \mathrm{~cm}$

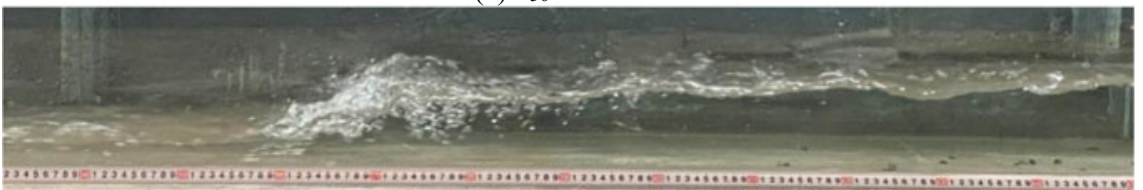

(d) $d_{50}=1.0 \mathrm{~cm}$

Fig. 7.2 Sudden stop of particles of varying sizes after a hydraulic jump

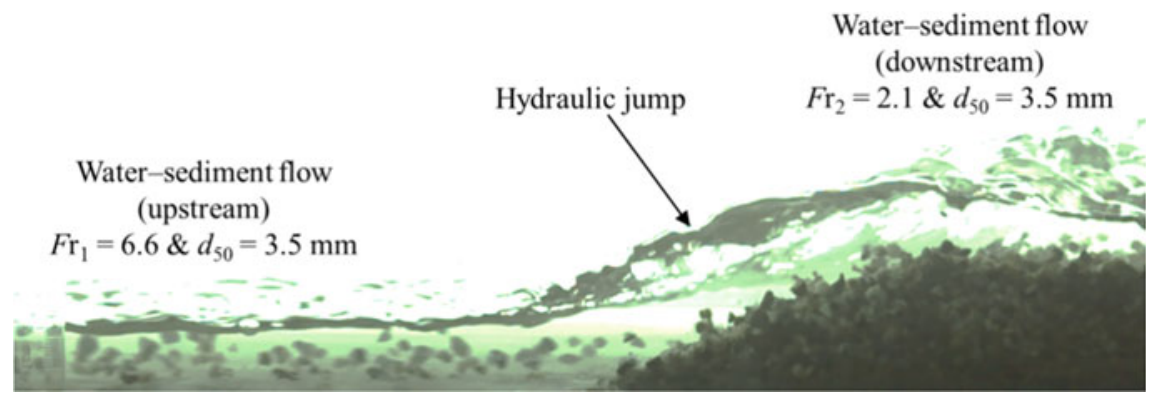

Fig. 7.3 Rapid sedimentation after a hydraulic jump

In a natural river, this process will eventually cause a flood and sediment disaster in a large area.

An accumulation body formed from extensive sedimentation was found to exhibit an undulating morphology with alternating peaks and troughs. Overall, the upstream peaks were higher than the downstream peaks. As the sediment accumulation body gradually developed upstream, its morphology continued to change with time. The flow regime in the whole accumulation zone exhibited notable variability (Fig. 7.6). 
a

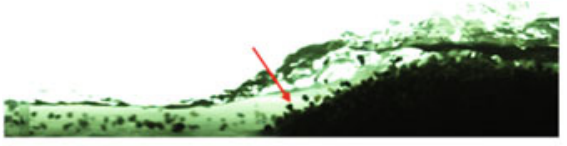

C

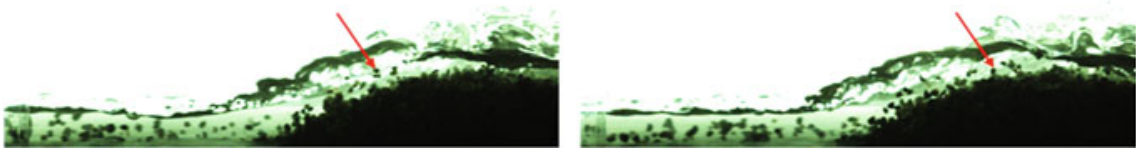

Fig. 7.4 Mesoscale deposition of sediment particles on an accumulation body

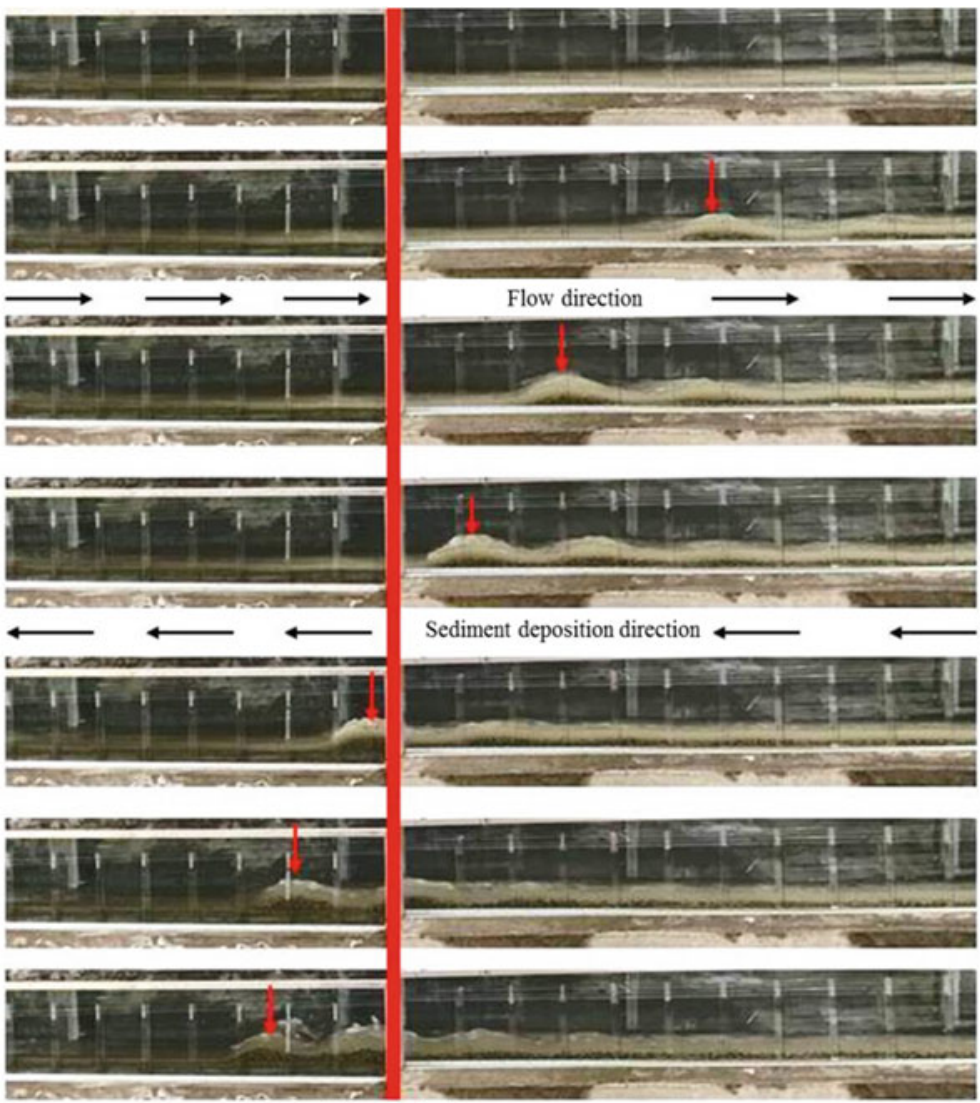

Slope variation

Fig. 7.5 Reverse development characteristics of a mound formed from sedimentation 


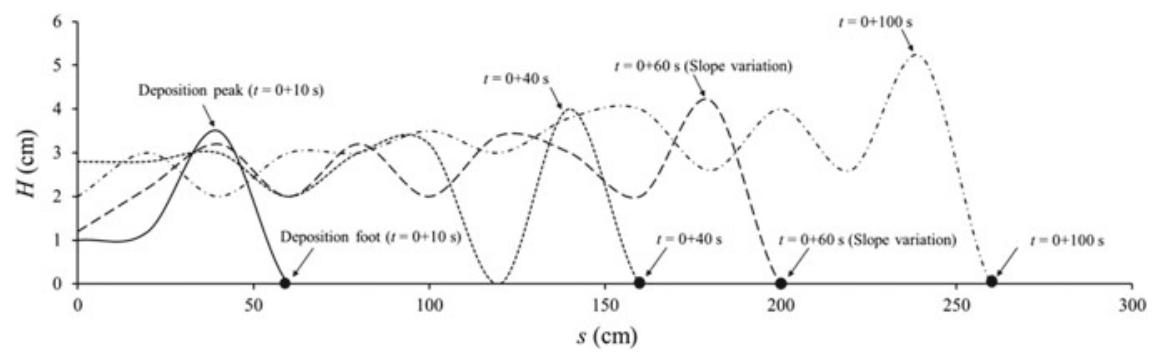

Fig. 7.6 Variation in the height of the sediment accumulation body, $H$, along the course

The variations in the rates of the reverse development $\left(V_{\mathrm{p}}\right.$ and $\left.V_{\mathrm{fe}}\right)$ of the peak and front edge, respectively, of the accumulation body formed from sedimentation with time fit a power function. At the initial stage of the formation of the accumulation body from sedimentation, $V_{\mathrm{p}}$ and $V_{\mathrm{fe}}$ were relatively high, and the accumulation body relatively rapidly developed upstream. As the accumulation body continuously developed upstream, $V_{\mathrm{p}}$ and $V_{\text {fe }}$ gradually decreased and tended to level off. Throughout the process, $V_{\mathrm{p}}$ and $V_{\text {fe }}$ were basically consistent with one another (Fig. 7.7).

Figure 7.8 shows the variation in the height of the sediment accumulation body, $H$, with time. As demonstrated in Fig. 7.8, at the initial stage, there was a relatively rapid increase in $H$. As time passed and the amount of accumulated sediment particles gradually increased, there was a gradual increase in $H$, but the rate of change in $H$ with time tended to level off.

Figure 7.9 shows a schematic diagram depicting the water level-discharge relationship during a large disaster caused by a small flood. In Fig. 7.9, the original oncein-two-year flood discharge corresponds to a relatively low water level. However, sedimentation on the riverbed raises the elevation of the riverbed and, thereby, raises water level. Under severe sedimentation conditions, there is a sharp rise in the water level that corresponds to a once-in-50-year flood discharge.

Fig. 7.7 Variations in the rates of reverse development $\left(V_{\mathrm{p}}\right.$ and $\left.V_{\mathrm{fe}}\right)$ of a sediment accumulation body

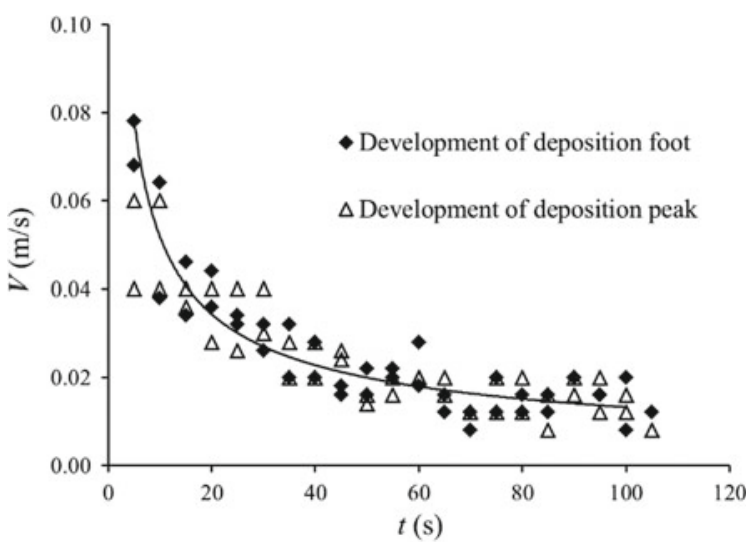




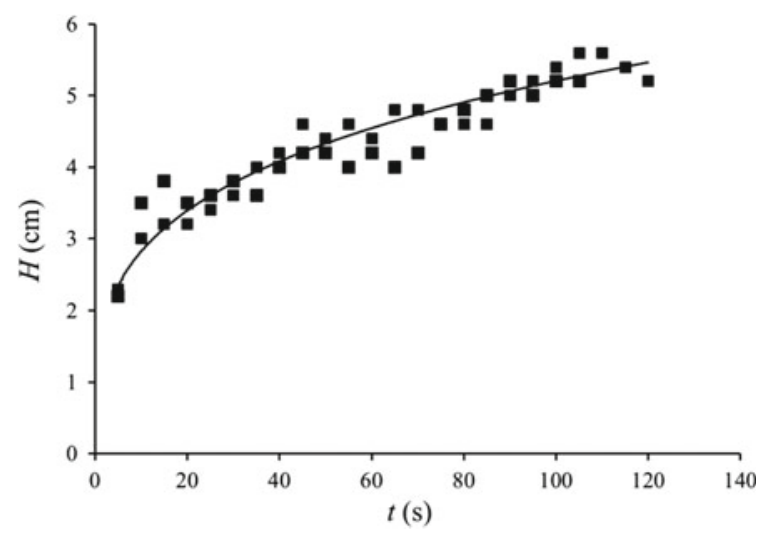

Fig. 7.8 Variation in the height of the sediment accumulation body, $H$, along the course

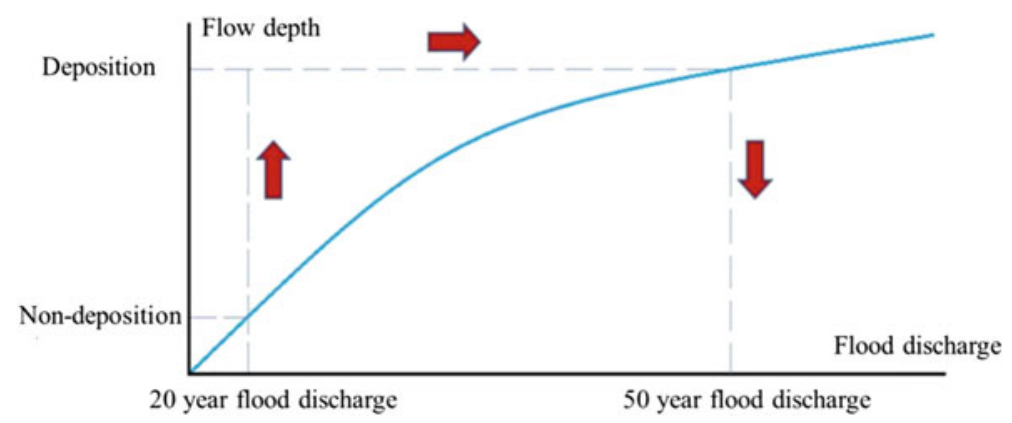

Fig. 7.9 Schematic diagram of a disaster caused by a small flood

\subsection{Threshold Conditions for Combined Flash Flood and Sediment Disasters}

The ratio of the number of particles that stopped suddenly and remained stationary after the hydraulic jump to the total number of particles that passed the hydraulicjump zone in the abovementioned experiment is defined as the dwelling ratio of the particles, $P_{\mathrm{d}}$. Statistical analysis has found that the median particle diameter $d_{50}$ and the ratio of the Froude number $F r$ of the flow upstream of a hydraulic jump to that of the flow downstream of the hydraulic jump, $\eta_{\mathrm{Fr}}$, are the main factors that affect $P_{\mathrm{d}} \cdot \eta_{\mathrm{Fr}}$ is calculated as follows:

$$
\eta_{F r}=\frac{F r_{1}}{F r_{2}}=\frac{U_{1} / \sqrt{g h_{1}}}{U_{2} / \sqrt{g h_{2}}}
$$




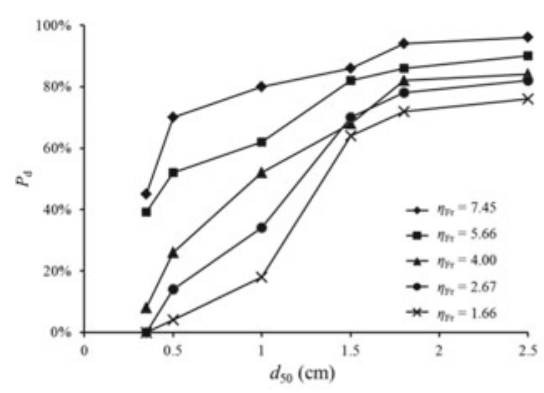

(a)

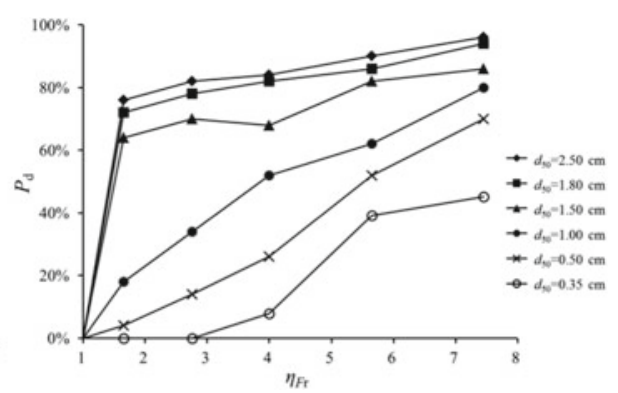

(b)

Fig. 7.10 Effects of the particle size and flow conditions on the dwelling ratio of particles, $P_{\mathrm{d}}$

where $U_{1}$ and $U_{2}$ are the flow velocities upstream and downstream of the hydraulic jump, respectively, and $h_{1}$ and $h_{2}$ are the water depths upstream and downstream of the hydraulic jump, respectively.

Figure 7.10 shows the experimental results for the $P_{\mathrm{d}}-d_{50}$ relationships corresponding to various $\eta_{\text {Fr }}$ values as well as the $P_{\mathrm{d}}-\eta_{\text {Fr }}$ relationships corresponding to various $d_{50}$ values. As demonstrated in Fig. 7.10, at a relatively low $\eta_{\mathrm{Fr}}$ and a relatively small $d_{50}$, all the particles were able to continuously move downstream, and none of the particles stopped and remained stationary. As $d_{50}$ and $\eta_{\mathrm{Fr}}$ increased, there was an increase in the number of particles that stopped and remained stationary as well as a gradual increase in $P_{\mathrm{d}}$.

In the presence of an adequate sediment supply, sediment particles will begin to accumulate at a certain $d_{50}$ and $\eta_{\mathrm{Fr}}$. The $\eta_{\mathrm{Fr}}$ when particles begin to accumulate is referred to as the threshold $\eta_{\mathrm{Fr}}$, which is denoted by $\eta_{\mathrm{Fr} 0}$. Thus, the threshold condition for particle accumulation at a certain $d_{50}$ is as follows:

$$
\eta_{F r}>\eta_{F r 0}
$$

As $\eta_{\mathrm{Fr} 0}$ is related to $d_{50}, \eta_{\mathrm{Fr} 0}$ varies significantly with $d_{50}$. During the accumulation of particles, the water level is not a direct factor independent of the flow velocity $U$. This suggests that when a threshold condition is established for FFSDs, the use of $d_{50}$ instead of the water level to establish a threshold index can comprehensively reflect the effects of $U$ and $d_{50}$. In fact, according to the bed-load motion theory, the sediment transport intensity of a bed load is directly proportional to the cube of the dimensionless parameter $U /\left(g d_{50}\right)^{1 / 2}$. In view of this, the flash-flood research team of the State Key Laboratory of Hydraulics and Mountain River Engineering of Sichuan University has defined $U /\left(g d_{50}\right)^{1 / 2}$ as the $F r$ of sediment (denoted $F r_{\mathrm{d}}$ ), i.e.,

$$
F r_{d}=\frac{U}{\sqrt{g d_{50}}}
$$


Thus, the threshold condition for rapid particle accumulation after a hydraulic jump can be represented by the following equation:

$$
\eta_{F r d}=\frac{F r_{d, 1}}{F r_{d, 2}}=\frac{U_{1} / \sqrt{g d_{50,1}}}{U_{2} / \sqrt{g d_{50,2}}}>\eta_{F r d 0}
$$

where $\eta_{\text {Frd }}$ is the ratio of the $F r_{\mathrm{d}}$ of the upstream sediment to that of the downstream sediment, the subscripts 1 and 2 signify upstream and downstream of the hydraulic jump, respectively, and the subscript 0 signifies the threshold value.

In natural rivers, sudden changes in $F r_{\mathrm{d}}$ can occur not only in variable-slope hydraulic-jump zones but also in mainstream-tributary confluence regions and widening regions. While the above threshold is derived from an analysis of the hydraulic jumps over variable slopes, it is also applicable to scenarios involving other types of morphological changes in rivers, as long a possible difference in $\eta_{\text {Frd0 }}$ is considered. Thus, the motion evolution of the water and sediment in reaches in mainstream-tributary confluence regions as well as widening regions is analyzed briefly in the following section.

Figure 7.11 shows the experimental results for the sediment accumulation in a reach in a mainstream-tributary confluence region (Lei et al. 2019). As demonstrated in Fig. 7.11, regardless of whether the confluence angle of the mainstream and the tributary was $30^{\circ}, 60^{\circ}$, or close to $90^{\circ}$, the transport of sediment stopped suddenly at the confluence when the $\eta_{\text {Frd }}$ for the water and sediment supplied by the tributary reached the threshold due to the backwater effect of the mainstream, leading to extensive sedimentation.

Figure 7.12 shows the numerical simulation results for sedimentation in a widening reach of a river (Zheng et al. 2016). Similarly, as demonstrated in Fig. 7.12, after the river widened suddenly, the emergence of flood land resulted in a sudden increase in the resistance of the riverbed and a significant decrease in $U$, which in turn resulted in a decrease in $F r_{\mathrm{d}}$. As a consequence, the ratio of the $F r_{\mathrm{d}}$ of upstream sediment to the $F r_{\mathrm{d}}$ of sediment at the location where the river widened exceeded the disaster threshold. This led to sedimentation.

To derive a more general expression of $\eta_{\text {Frd }}$, it is necessary to collect and analyze a wide range of flash-flood data for various regions of natural rivers. On this basis, a threshold condition with general applicability for FFSDs can be established.

The State Key Laboratory of Hydraulics and Mountain River Engineering of Sichuan University collected and analyzed data for several hundreds of flash floods and eventually derived a threshold condition $\eta_{\text {Frd0 }}$ for combined flash flood and sediment disasters, as shown in Fig. 7.13. 


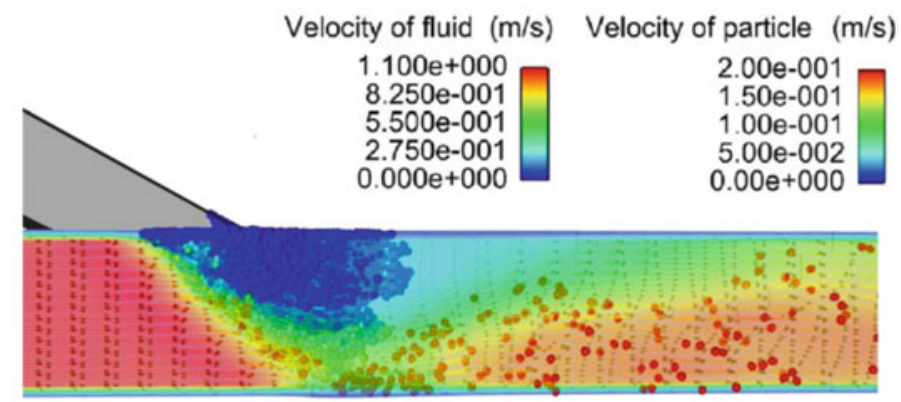

(a)

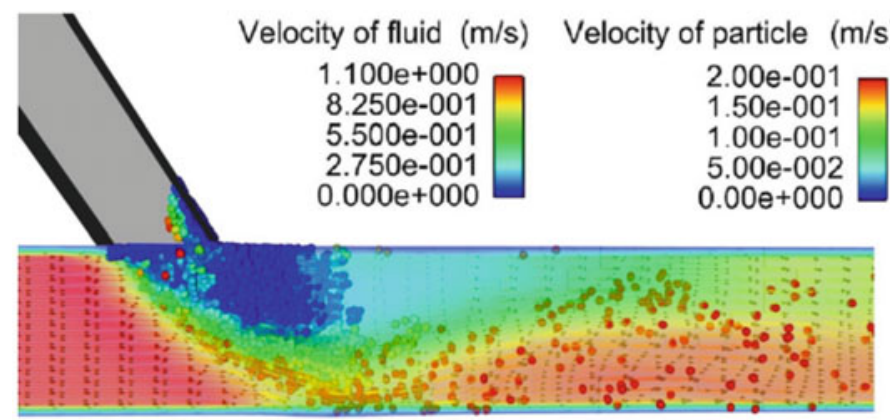

(b)

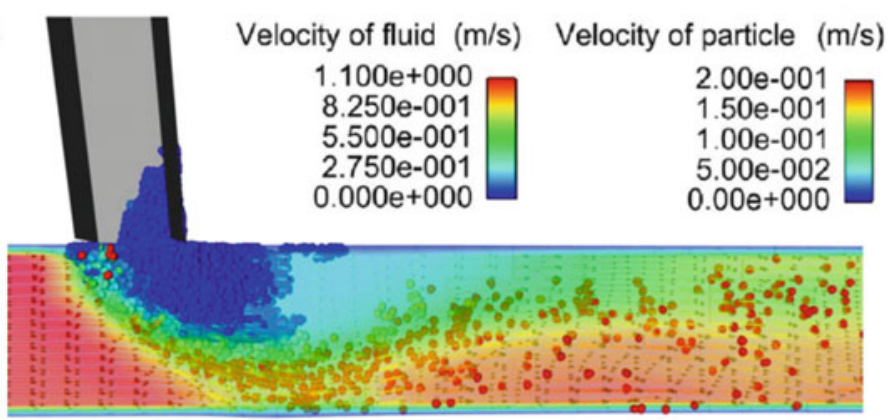

(c)

Fig. 7.11 Sedimentation in a reach in a mainstream-tributary confluence region

\subsection{Identification of Disaster-Prone Regions Based on the Threshold Conditions for Combined Flash Flood and Sediment Disasters}

This section briefly introduces a system developed by the State Key Laboratory of Hydraulics and Mountain River Engineering of Sichuan University based on $\eta_{\text {Frd0 }}$ to identify FFSD-prone regions. 


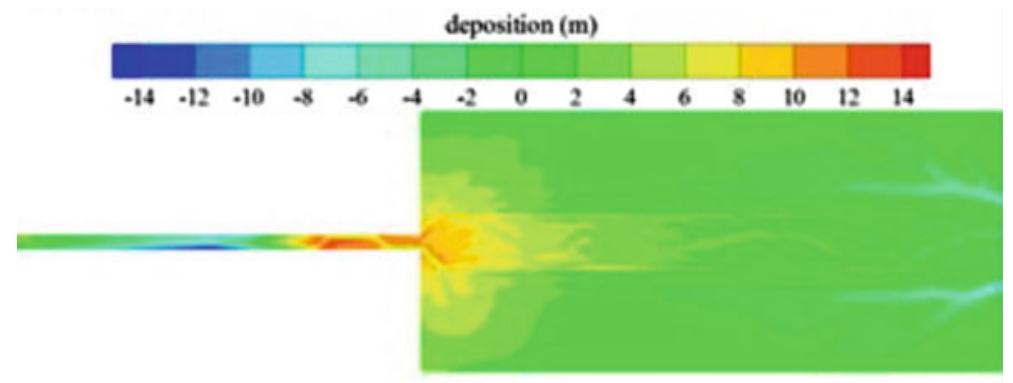

(a)

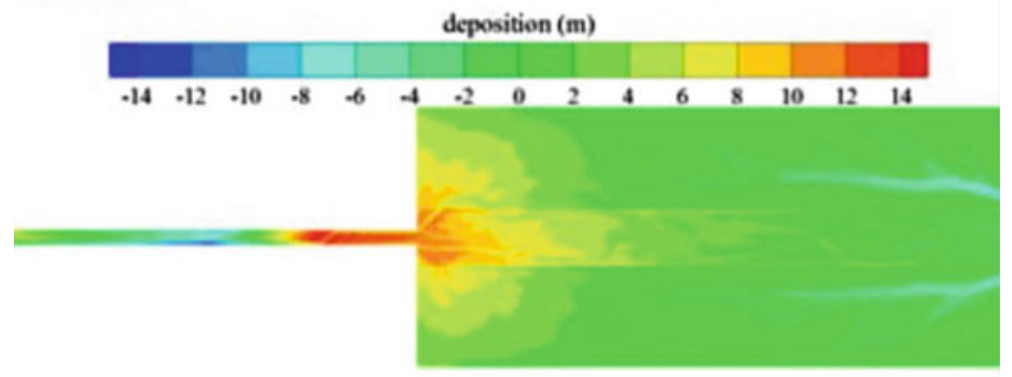

(b)

Fig. 7.12 Sedimentation in a widening reach of a river

Fig. 7.13 Threshold condition for combined flash flood and sediment disasters

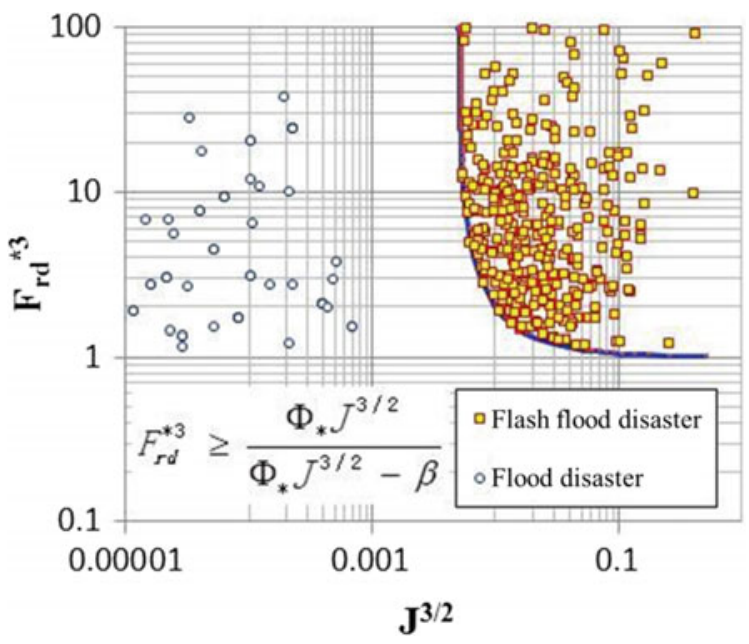


Conventionally, the risk of flash floods is primarily classified using the following method: The areas affected by floods of various frequencies are first determined based on their water level values. Then, the risk levels are determined based on the flood frequencies. This risk classification method is completely reasonable and feasible for normal floods. However, for FFSDs involving large amounts of sediment, this method is problematic because it underestimates the risk and is inaccurate in predicting the locations at risk.

On the basis of the threshold condition $\eta_{\text {Frd } 0}$ for combined flash flood and sediment disasters and an FFSD simulation model, a more accurate risk identification system for FFSD-prone regions can be established to accurately identify real-world FFSDs.

First, for the FFSD-prone region whose risk is to be determined, as detailed of terrain data as possible and the possible upstream sediment supply conditions must be obtained. These data provide the fundamental conditions for identifying the risk of the FFSD-prone region.

Second, the sites prone to disasters under combined flood and sediment conditions are determined by hydraulic calculations based on $\eta_{\text {Frd0 }}$ (Fig. 7.14). $\eta_{\text {Frd0 }}$ is primarily controlled by $F r_{\mathrm{d}}$, which changes suddenly mainly in regions where the base slope of the riverbed levels off sharply, mainstream-tributary confluence regions, and sharply widening river reaches. Thus, particular attention should be paid to these regions.

Finally, simulations are performed using the FFSD model, with the FFSD-prone sites identified based on $\eta_{\text {Frd0 }}$ to further identify the specific areas at risk. The results can be used to guide the formulation of emergency plans and the provision of disaster warnings (Fig. 7.15).

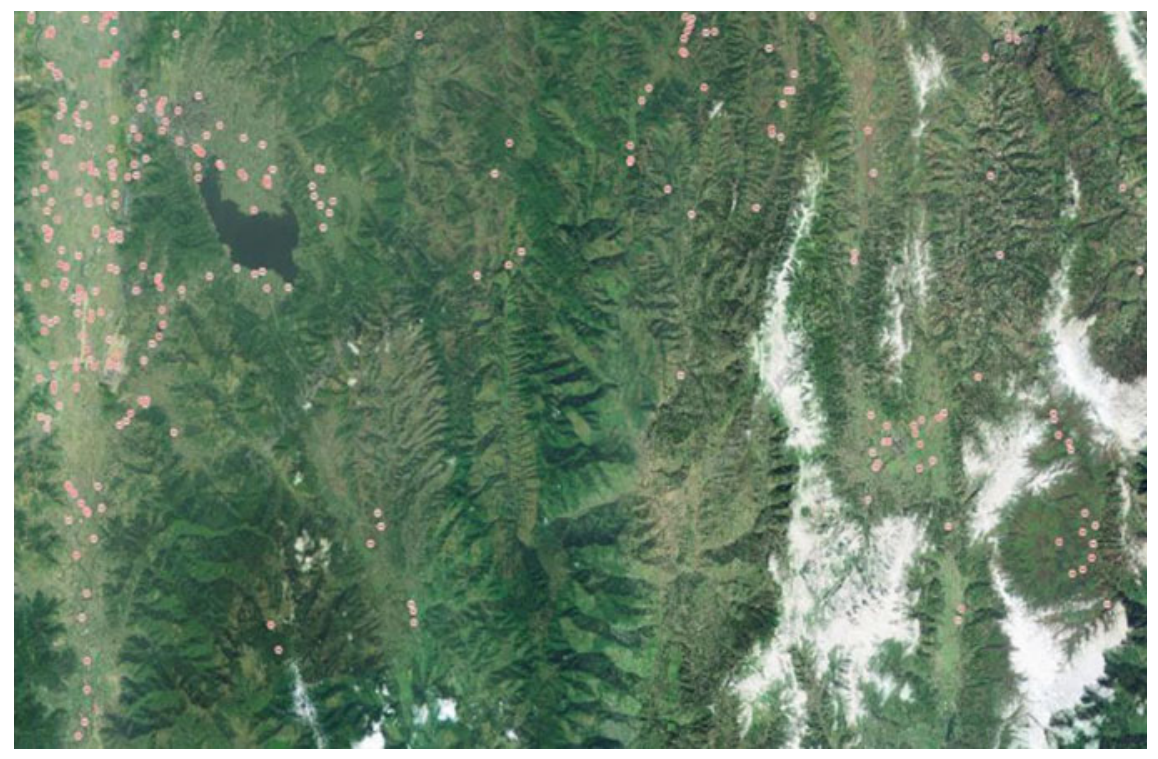

Fig. 7.14 Identification of the FFSD-prone sites 

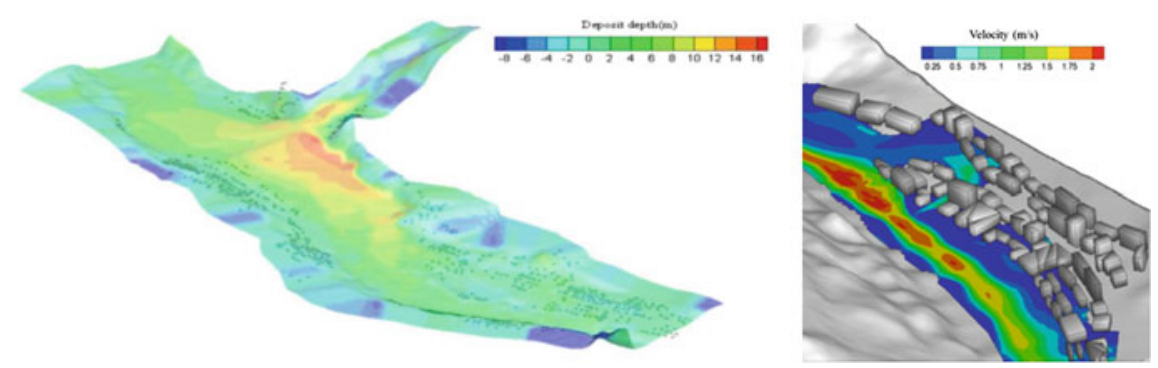

Fig. 7.15 Simulations of a region prone to disasters under combined flash flood and sediment conditions

Most prominently, the above risk identification method for disaster-prone regions has relatively high accuracy regarding the identification of the location and area of each disaster-prone site. Compared to water level analysis methods that do not consider the disaster effect of sedimentation, this method improves the accuracy by identifying the risk in FFSD-prone regions from an "area" level to a "point" level. As demonstrated in Fig. 7.16, the locations of the disaster-prone sites identified by

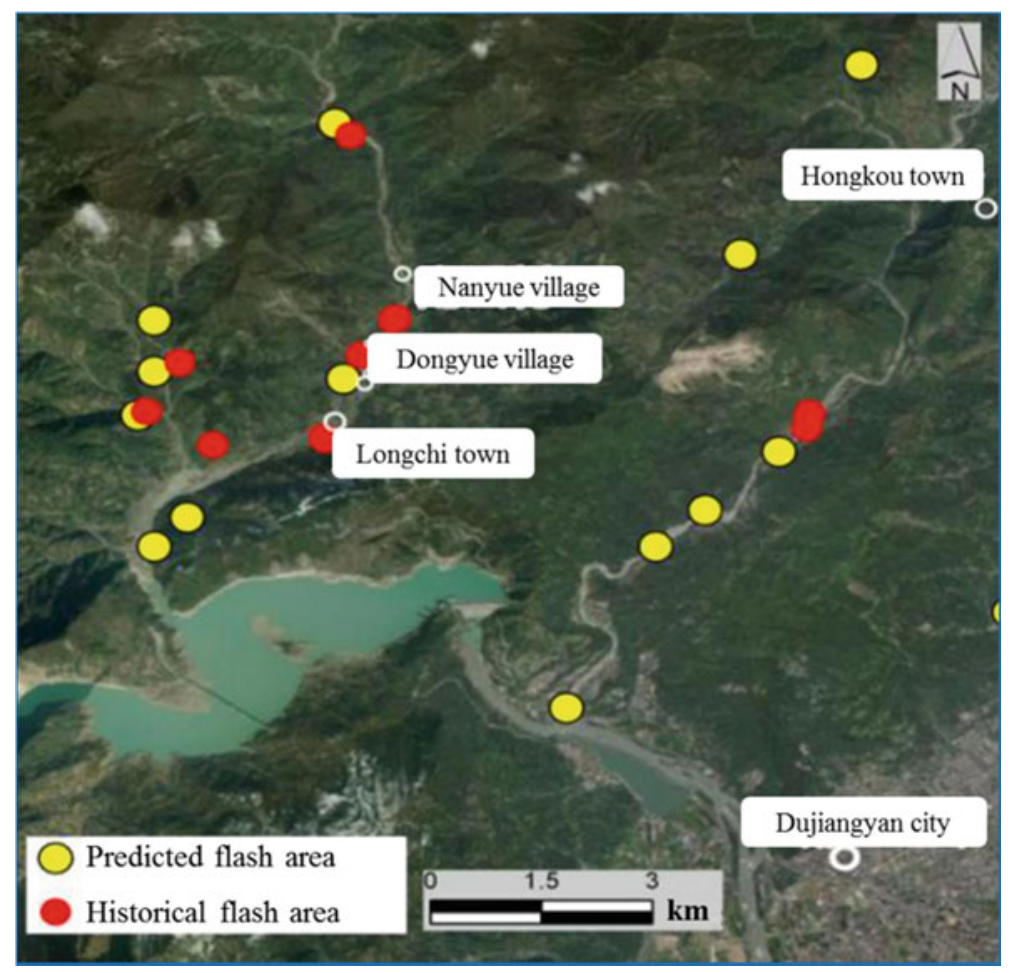

Fig. 7.16 Identification of FFSD-prone sites with an accuracy of 1-2 km 


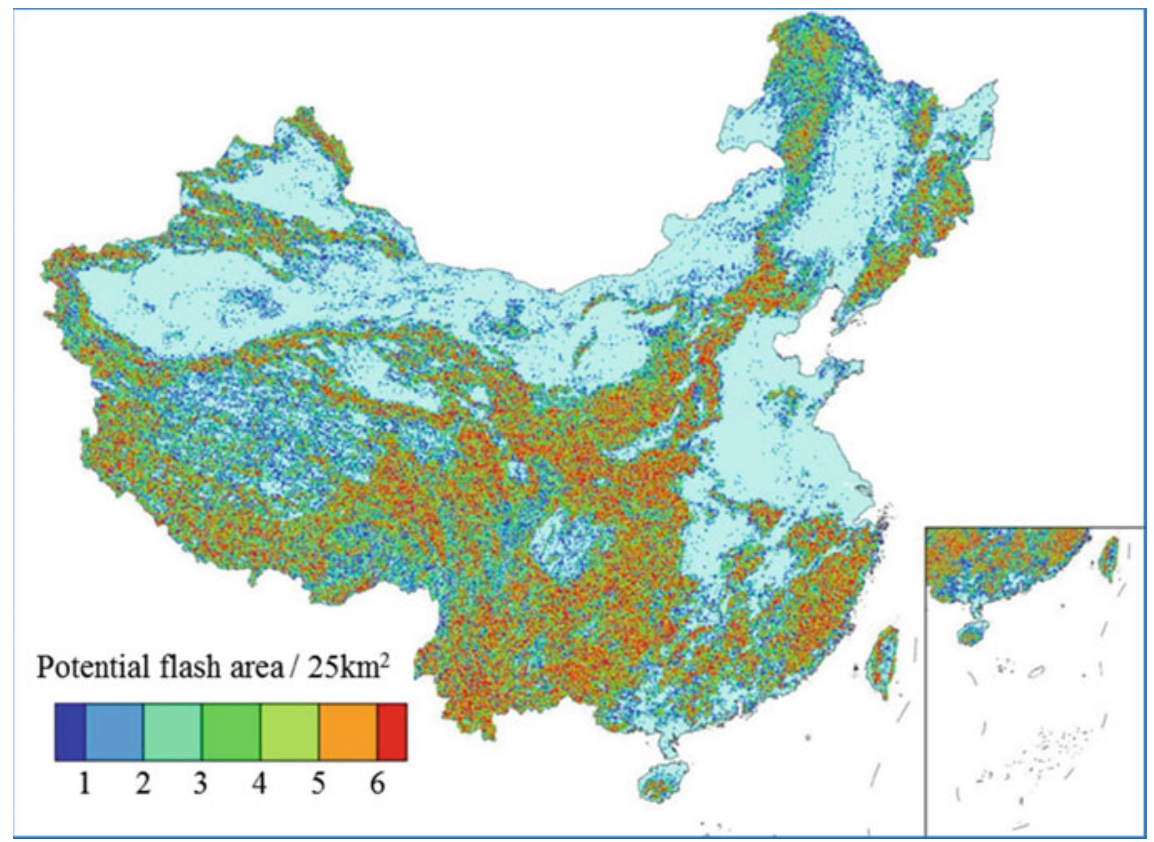

Fig. 7.17 Identification results produced by a risk identification system for FFSD-prone regions

this method are very close to those of the real-world sites where FFSDs occurred. This suggests that this identification method is effective.

The above identification method can be employed to establish a new risk identification system for FFSD-prone regions that covers all of China or even the entire globe (Fig. 7.17). This system can be first established based on open terrain data. Subsequently, users can supplement the system with new, higher-accuracy local terrain data according to their needs to improve its identification accuracy while using it. This will lead to continuous improvement in the identification accuracy of the system on the global scale. Ultimately, FFSD-prone regions can be accurately identified using this system.

Two issues are worthy of discussion, namely, the randomness and uncertainty of FFSDs and the acquisition of terrain data.

FFSDs depend primarily on three factors, namely, local river conditions, regional rainfall conditions, and upstream sediment supply. Of these three factors, the local river conditions are certain, and the regional rainfall conditions can now be determined based on 3-24 h rainfall forecasts, whereas the upstream sediment supply is notably uncertain. The above system is referred to as a risk identification system for disaster-prone regions because its core aim is to identify disaster-prone regions rather than to directly predict disasters. In other words, this system first determines whether local rivers are prone to disasters based on whether their $F r_{\mathrm{d}}$ values reach the disaster threshold as well as the sizes of the disaster-prone regions corresponding to various 
inflow conditions. Then, based on rainfall forecasts, this system determines whether it is possible for the rainfall to induce FFSDs in the presence of a sufficient sediment supply. If possible, the system will give a warning regardless of whether there is a sufficient sediment supply. In essence, this method addresses the uncertainty of upstream sediment supply conditions by increasing the number of warnings.

Terrain data are basic data for a risk identification system for FFSD-prone regions. The accuracy of terrain data, to a large extent, dictates the identification accuracy. Generally, terrain data can be obtained from digital elevation models (DEMs). However, when DEM data are unable to meet the identification accuracy requirements, it is necessary to obtain terrain data by specific field measurements, e.g., unmanned aerial vehicle surveys.

\subsection{Analysis of Control Techniques Based on the Threshold Conditions for Combined Flash Flood and Sediment Disasters}

The occurrence of an FFSD is dependent on the river regime, heavy rainfall, an excessive sediment supply, and human activity (Montgomery et al. 1996; Chatanantavet and Parker 2008). The key to FFSD control is to control $F r_{\mathrm{d}}$ below the threshold by adjusting the river regime. Based on the definition of $F r_{\mathrm{d}}$, FFSD control techniques can be developed from the perspectives of adjusting the $U$ values upstream and downstream of a disaster-prone river reach and the $d_{50}$ of sediment particles. Specifically, $\eta_{\text {Frd }}$ can be maintained below $\eta_{\text {Frdo }}$ by reducing the upstream $U$ or increasing the downstream $U$ as well as by increasing the $d_{50}$ of the upstream sediment or reducing the $d_{50}$ of the downstream sediment.

Some typical available FFSD control techniques conform to the above principle. Naturally, when a specific control scheme is designed, it is necessary to determine its parameters based on $\eta_{\text {Frd0 }}$.

Wang et al. propounded a training levee line control technique for mainstreamtributary confluence regions (Wang et al. 2015; Gao et al. 2020), which is referred to as "control by diverting water" (Fig. 7.18). In this technique, the outline of the point bar formed by scouring is first determined, and the threshold $U$ for the point-bar sediment particle movement is calculated. Then, a mathematical model is used to calculate the $U$ distribution at the design standard flood discharge. Subsequently, the contour line of the $U$ threshold for point-bar sediment particle movement at the outer outline of the point bar in the $U$ distribution is used as a point-bar control line. If conditions permit, the confluence angle between the mainstream and the tributary should be minimized in each confluence region. From the perspective of controlling $F r_{\text {d }}$, this technique, in essence, reduces $\eta_{\text {Frd }}$ and controls it within the safe range by reducing the width of the downstream river as well as increasing the downstream $U$ and downstream $\mathrm{Fr}_{\mathrm{d}}$. 

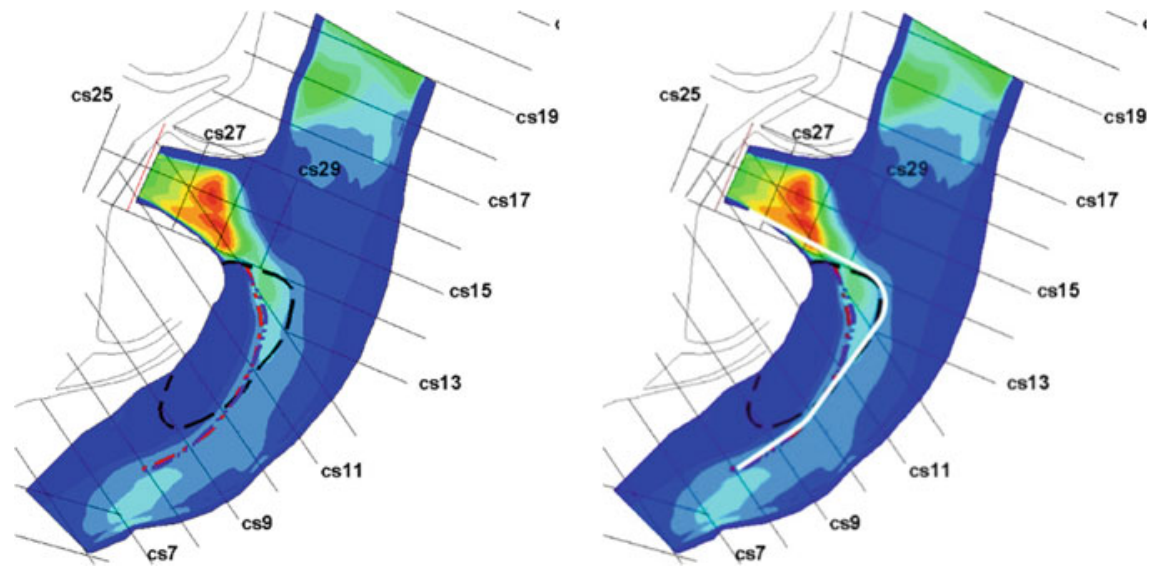

Fig. 7.18 Control by diverting water

Placing sediment-trap dams in rivers or streams is another typical FFSD control technique, which is referred to as "control by trapping sediment". A bottom current flow connection downstream of a relatively high sediment-trap dam can easily scour and damage the downstream riverbed. To address this problem, energy dissipation structures can be placed downstream of the dam in locations at various elevations. After passing the dam, a flow first enters the body of water where the first-level energy dissipation structure is located, and its energy is partially consumed. Subsequently, the flow enters the body of water where the second-level energy dissipation structure is located, and its energy is further consumed. Thus, through energy dissipation in a cascading manner, the flow enters the river downstream of a sediment-trap dam at a relatively low $U$ after passing the dam. This approach not only fully realizes the role of a sediment-trap dam in trapping sediment but also effectively prevents the riverbed downstream of the dam from being scoured and damaged. Figure 7.19 shows a sediment-trap dam technique capable of dissipating energy and preventing scouring. From the perspective of controlling $F r_{\mathrm{d}}$, sediment trapping alters $\eta_{\text {Frd }}$ by increasing the $d_{50}$ of the upstream sediment and decreasing that of the downstream sediment. As sediment traps often have a damming effect to varying degrees, sediment trapping also generally reduces the upstream $U$. These effects reduce $\eta_{\text {Frd }}$ to below $\eta_{\text {Frd0 }}$.

Ma et al. proposed a technique that involves the placement of structures that separate water and sediment in spillways (Zhong et al. 2019), which is referred to as "control by separating sediment" (Fig. 7.20). The core of this technique is described as follows: A sediment accumulation pool is placed at the upstream end. A flow passageway and a sediment discharge passageway are established in parallel downstream of the sediment accumulation pool. The entrance of the sediment discharge passageway is connected smoothly with the sediment accumulation pool. An overflow weir is placed upstream of the flow passageway. The upstream side of the overflow weir doubles as a sediment diversion wall and can divert large sediment particles into the sediment discharge passageway and prevent them from entering the 

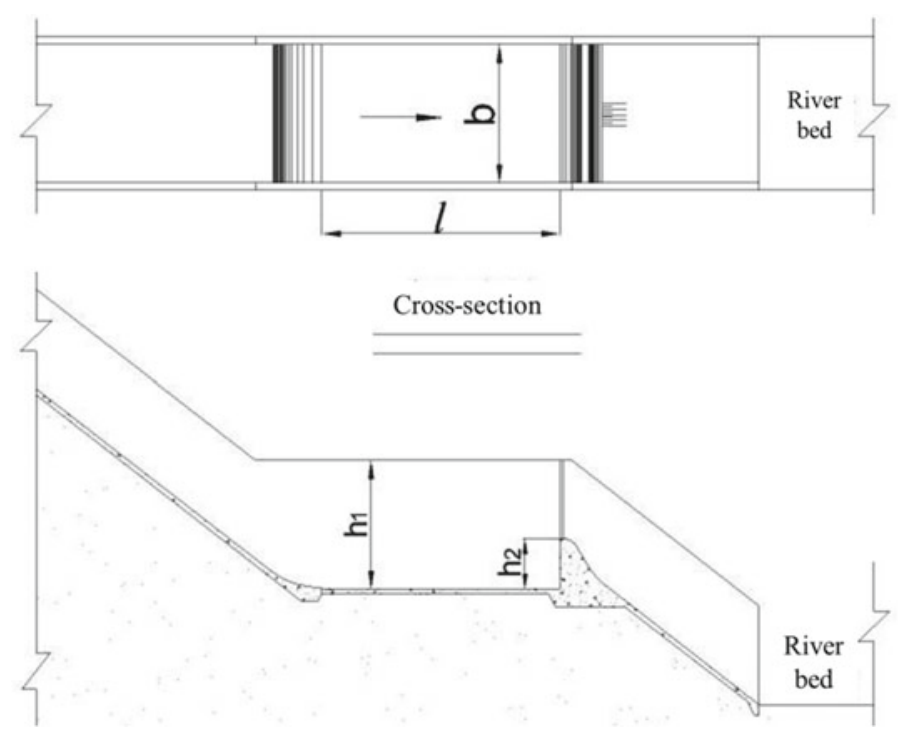

Fig. 7.19 Control by trapping sediment

downstream river and, thereby, reduce the $d_{50}$ of the downstream sediment. From the perspective of controlling $F r_{\mathrm{d}}$, sediment separation reduces $\eta_{\text {Frd }}$ by reducing the $d_{50}$ of the downstream sediment.

Wang et al. (2014) and Lei et al. (2019) formulated a peak-staggering sedimentarresting pier technique capable of mitigating siltation in mountainous rivers, which is referred to as "control by staggering the peaks" (Fig. 7.21). According to this technique, at least three peak-staggering sediment-arresting piers in two rows are required based on the locations of the concentrated flow paths of the median-water and flood periods and the maximum thickness of the accumulated sediment after the recession of floods. Each sediment-arresting pier is placed outside the concentrated flow paths of the median-water period but within the concentrated flow paths of the flood period. Thus, the sediment-arresting piers do not affect the flow movement during the median-water and dry periods. During the sediment disaster-prone flood period, these piers arrest sediment and, thereby, cause the sediment peak to occur after the flood peak and decouple the flood and sediment processes. From the perspective of controlling $F r_{\mathrm{d}}$, peak staggering, which is the temporal and spatial separation of the flood and sediment peaks, reduces $\eta_{\text {Frd }}$ by increasing the $d_{50}$ of the upstream sediment as well as decreasing the $d_{50}$ of the downstream sediment and the upstream $U$.

Figure 7.22 shows a real-world example of the engineering control of a mainstream-tributary confluence region. This region suffered severe siltation because of a flash flood. As a result, the village, schools, and enterprises sustained enormous losses. After the disaster, multiple mainstream-tributary confluence regions were 

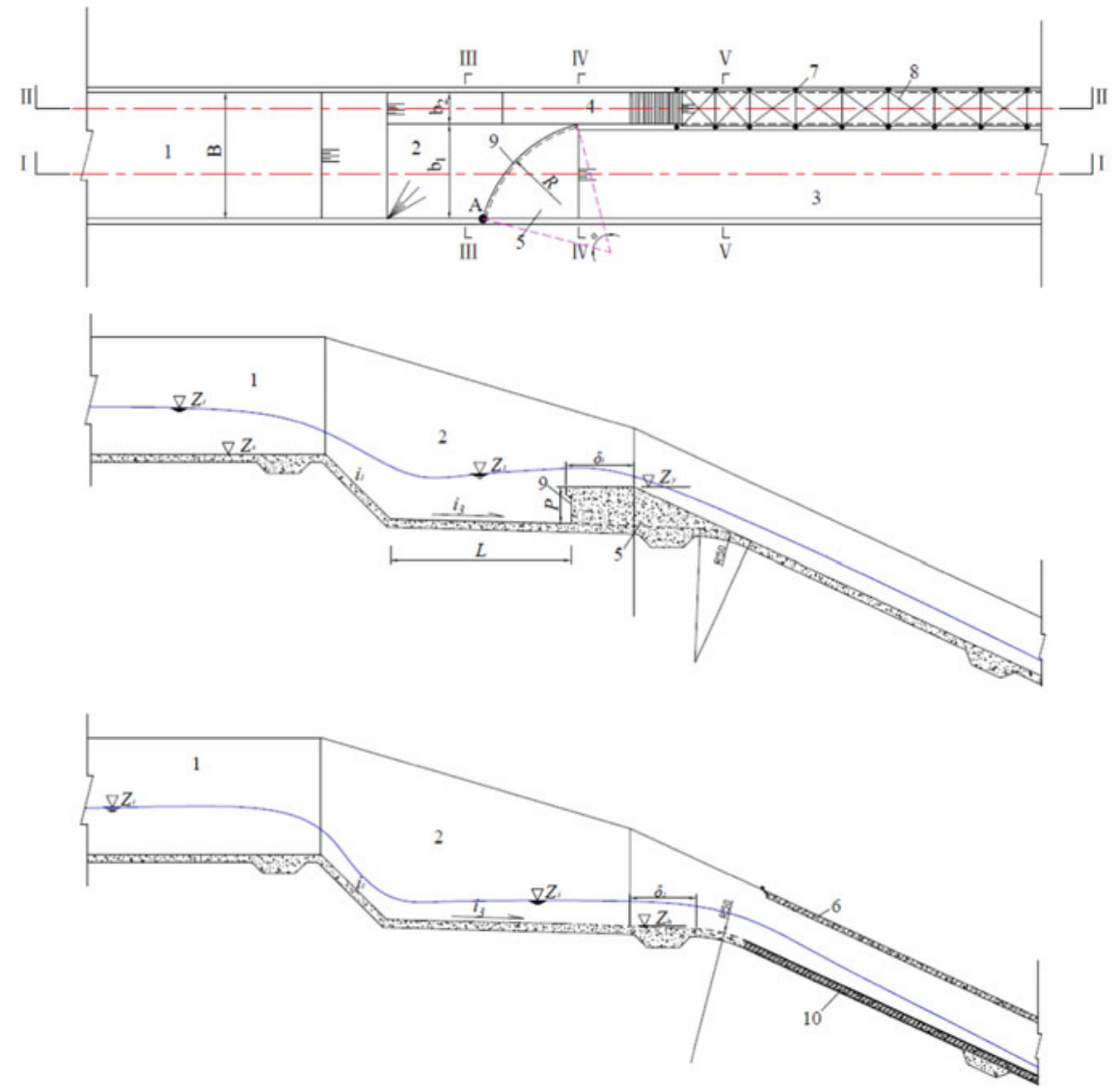

Fig. 7.20 Control by separating sediment
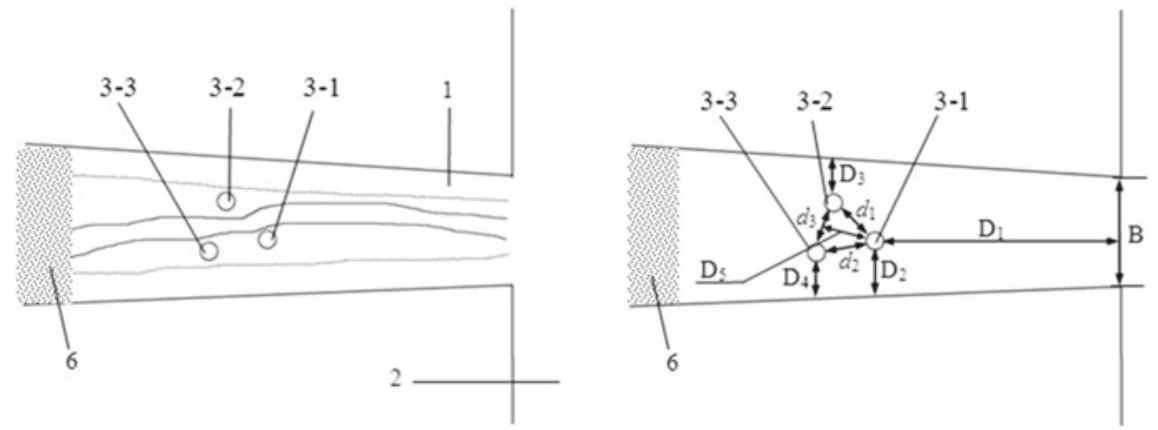

Fig. 7.21 Control by staggering the peaks 


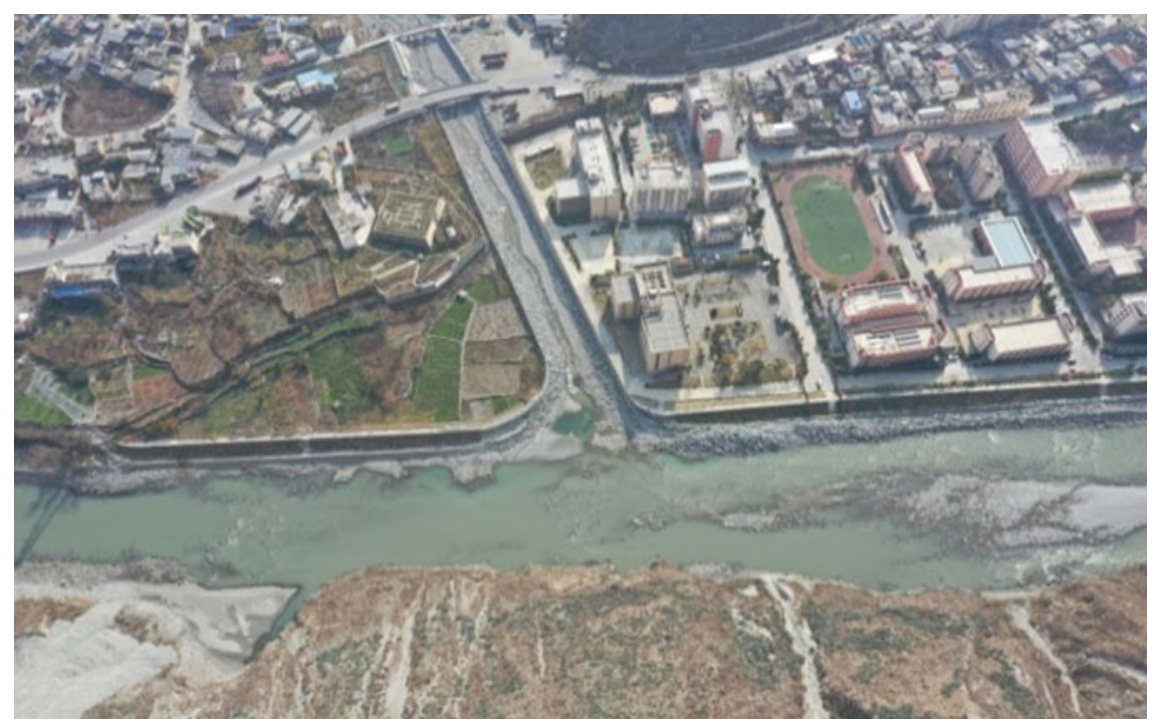

Fig. 7.22 Real-world example of the engineering control of a mainstream-tributary confluence region

controlled along the mainstream. The reaches controlled using conventional techniques were again extensively damaged during subsequent flash floods. In contrast, the reach shown in Fig. 7.22 was controlled based on the threshold $F r_{\mathrm{d}}$. Specifically, the downstream side of the end of the tributary was straightened. In addition, the angle at which the tributary flew into the mainstream was reduced. This approach prevented a sudden decrease in the $F r_{\mathrm{d}}$ of the downstream sediment due to the expansion and thrust of the flow and ensured that $\eta_{\text {Frd }}$ was below the threshold. After the implementation of the control measures, the confluence region remained safe during the flood season and withstood a subsequent catastrophic FFSD.

\subsection{Conclusions}

The following main conclusions can be derived from the analysis in this chapter:

1. The mesoscale investigation of the hydraulic jump of a sediment-laden flow shows that sediment particles suddenly stop moving after entering the slowflow section from the rapid-flow section and, subsequently, accumulate in large amounts. In addition, the front edge of the accumulation body continuously develops upstream as a result of the interactions between the flow and sediment particles. This in turn causes the front of the hydraulic jump to move upstream and, thereby, results in chain-type sedimentation and a rise in the water level. 
2. The threshold condition for combined flash flood and sediment disasters can be represented by $\eta_{\text {Frd }}$, which is the ratio of the Froude number of the upstream sediment to that of downstream sediment. When $\eta_{\text {Frd }}$ reaches the threshold, rapid sedimentation occurs, the riverbed rises sharply, and water level rises suddenly. This leads to an increase in the risk of a disaster and can even allow a small flood to cause a large disaster.

3. The principle of controlling the sediment Froude number $F r_{\mathrm{d}}$ can be used to design engineering control schemes for FFSDs. It is necessary to ensure that $\eta_{\text {Frd }}$ is below the disaster threshold in design.

\section{References}

Borga, M., Boscolo, P., Zanon, F., \& Sangati, M. (2007). Hydrometeorological analysis of the 29 August 2003 flash flood in the Eastern Italian Alps. Journal of Hydrometeorology, 8(5), 1049-1067.

Chatanantavet, P., \& Parker, G. (2008). Experimental study of bedrock channel alluviation under varied sediment supply and hydraulic conditions. Water Resources Research, 44(12).

Dietrich, W. E., Kirchner, J. W., Ikeda, H., \& Iseya, F. (1989). Sediment supply and the development of the coarse surface layer in gravel-bedded rivers. Nature, 340(6230), 215-217.

Diplas, P., Dancey, C. L., Celik, A. O., Valyrakis, M., Greer, K., \& Akar, T. (2008). The role of impulse on the initiation of particle movement under turbulent flow conditions. Science, 322(5902), 717-720.

Gao, Y., Ye, L., Wang, Y., Xu, Z., \& Wang, X. (2020). 3D numerical simulation of flow characteristics at confluence zone between Shenxigou Stream and Baisha River. Advanced Engineering Sciences, 52(2), 78-85.

Lei, M., Xu, Z.-X., Zhao, T., \& Wang, X.-K. (2019a). Dynamics of loose granular flow and its subsequent deposition in a narrow mountainous river. Journal of Mountain Science, 16(6), 13671380.

Lei, M., Yu, H., Xu, Z., \& Wang, X. (2019b). Numerical simulation of retrogressive pebble deposition in the changing slope zone of a mountainous river. Advanced Engineering Sciences, 51(1), 45-51.

Madej, M. A., Sutherland, D. G., Lisle, T. E., \& Pryor, B. (2009). Channel responses to varying sediment input: A flume experiment modeled after Redwood Creek, California. Geomorphology, 103(4), 507-519.

Montgomery, D. R., Abbe, T. B., Buffington, J. M., Peterson, N. P., Schmidt, K. M., \& Stock, J. D. (1996). Distribution of bedrock and alluvial channels in forested mountain drainage basins. Nature, 381(6583), 587-589.

Wang, X., Ye, L., Wang, Yu., \& Liu, X. (2014). Experimental study on the evolution of the accumulation body in the confluence due to steep gully of the high intensity sediment transport. Journal of Sichuan University (Engineering Science Edition), 5, 7-13.

Wang, B., Zhou, S., Wang, H., Wang, X., \& Liu, T. (2015). Regulation method in right-angled river confluence. Journal of Sichuan University (Engineering Science Edition), S1, 7-12.

Wang, X., Liu, X., \& Zhou, J. (2019). Research framework and anticipated results of flash flood disasters under the mutation of sediment supply. Advanced Engineering Sciences, 51(4), 1-10. 
Zheng, X.-G., Pu, J. H., Chen, R.-D., Liu, X.-N., \& Shao, S. (2016). A novel explicit-implicit coupled solution method of SWE for long-term river meandering process induced by dam break. Zhong, Y., Ma, X., Nie, R., Liu, X., \& Zheng, X. (2019). Experimental study on the effect of siltation height on water level change in steep slope channel. Advanced Engineering Sciences, 51(6), 134-138.

Open Access This chapter is licensed under the terms of the Creative Commons AttributionNonCommercial 4.0 International License (http://creativecommons.org/licenses/by-nc/4.0/), which permits any noncommercial use, sharing, adaptation, distribution and reproduction in any medium or format, as long as you give appropriate credit to the original author(s) and the source, provide a link to the Creative Commons license and indicate if changes were made.

The images or other third party material in this chapter are included in the chapter's Creative Commons license, unless indicated otherwise in a credit line to the material. If material is not included in the chapter's Creative Commons license and your intended use is not permitted by statutory regulation or exceeds the permitted use, you will need to obtain permission directly from the copyright holder. 